Supplement of Biogeosciences Discuss., 11, 9813-9852, 2014

http://www.biogeosciences-discuss.net/11/9813/2014/

doi:10.5194/bgd-11-9813-2014-supplement

(C) Author(s) 2014. CC Attribution 3.0 License.

(c) (i)

Supplement of

\title{
Methane related changes in prokaryotic activity along geochemical pro- files in sediments of Lake Kinneret (Israel)
}

\section{Bar Or et al.}

Correspondence to: A. Kushmaro (arielkus@bgu.ac.il) 
Supplementary Table S1. Bacterial Morisita-Horn similarity indexes between the different depths. Class values are followed by phyla values in parentheses. Sequences with unknown classifications were not counted in the statistic analysis.

\begin{tabular}{llll} 
Bacteria & Depth 0-3 cm & Depth 6-9 cm & Depth 29-32 cm \\
\hline Depth 0-3 cm & & $0.413(0.652)$ & $0.501(0.56)$ \\
Depth 6-9 cm & $0.413(0.652)$ & & $0.89(0.925)$ \\
\hline
\end{tabular}

Supplementary Table S2. Archaeal Morisita-Horn similarity indexes between the different depths. Class values are followed by phyla values in parentheses. Sequences with unknown classifications were not counted in the statistic analysis.

\begin{tabular}{llll}
\hline Archaea & Depth 0-3 cm & Depth 6-9 cm & Depth 29-32 cm \\
\hline Depth 0-3 cm & & $0.982(0.997)$ & $0.857(0.872)$ \\
Depth 6-9 cm & $0.982(0.997)$ & & $0.924(0.954)$ \\
\hline
\end{tabular}

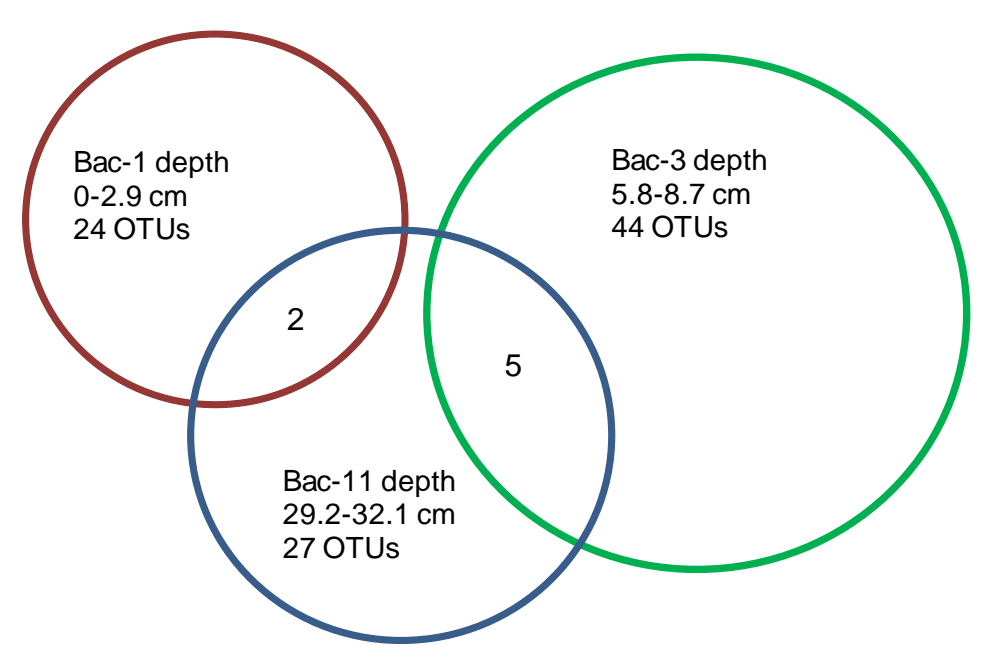

Supplementary Fig. 1. Venn diagram showing bacterial OTU overlap between the different depths. The red circle represents the top sample $(0-2.9 \mathrm{~cm})$, the green circle represents the middle sample $(5.8-8.7 \mathrm{~cm})$ and the blue circle represents the bottom sample $(29.2-32.1 \mathrm{~cm})$. 


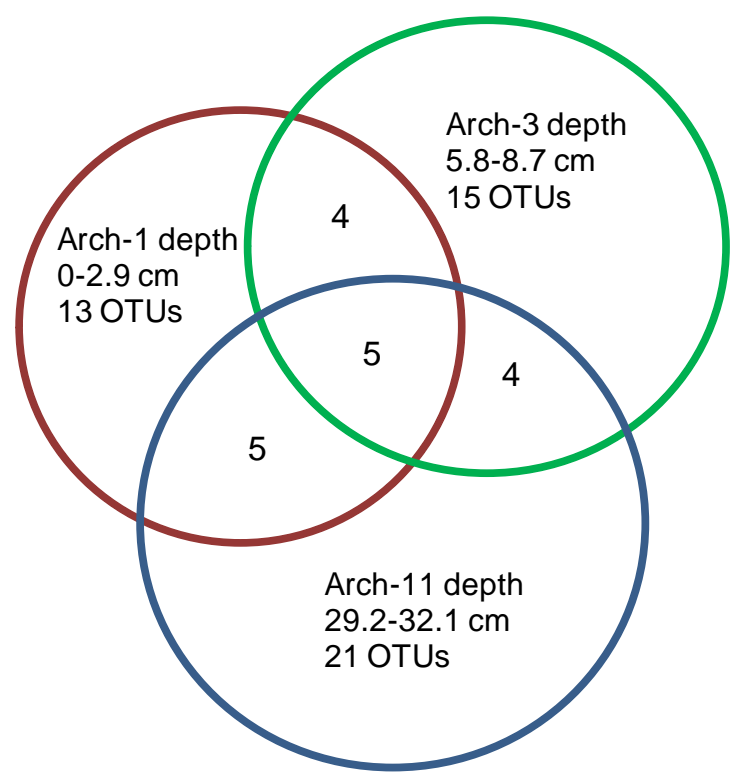

Supplementary Fig. 2. Venn diagram showing archaeal OTU overlap between the different depths. The Red circle represents the top sample $(0-2.9 \mathrm{~cm})$, the green circle represents the middle sample $(5.8-8.7 \mathrm{~cm})$ and the blue circle represents the bottom sample $(29.2-32.1 \mathrm{~cm})$. 